\title{
Study on precipitated phases, dislocations and hardness in the HAZ of friction stir welded joint of 2024 aluminum alloy
}

\author{
Peng $\mathrm{Liu}^{1 *}$, Keyun Feng ${ }^{1}$, Shubo Xu${ }^{1}$, Geming Zhang ${ }^{1}$, Meiqing $\mathrm{Cao}^{2}$, Jianing $\mathrm{Li}^{1}$, \\ Chuanwei $\mathrm{Shi}^{1}$
}

\author{
${ }^{1}$ School of Materials Science and Engineering, Shandong Jianzhu University, Jinan 250101, Shandong, P. R. China \\ ${ }^{2}$ School of Materials Science and Engineering, Shandong University of Science and Technology, \\ Qingdao 266590, P. R. China
}

Received 15 December 2016, received in revised form 6 March 2017, accepted 7 March 2017

\begin{abstract}
The microhardness, precipitated phases and dislocations in the heat-affected zone of friction stir welded joints of 2024 aluminum alloys were observed and analyzed by transmission electron microscopy. The test result indicated that there were some block precipitation particles, $\mathrm{Al}_{7} \mathrm{Cu}_{3} \mathrm{Mg}_{6}$ phase, in the $\mathrm{HAZ}$ close to advancing side. The precipitated $\mathrm{AlCu}_{3}$ phase can be observed in the $\mathrm{HAZ}$ close to retreating side. $\mathrm{Al}_{7} \mathrm{Cu}_{3} \mathrm{Mg}_{6}$ phase could enhance the hardness in the advancing side of joint. After $\mathrm{FSW}, \mathrm{AlCu}_{3}$ precipitated phase and high-density dislocations were divided into some fine particles and the lower dislocation density regions, respectively. As a result, the hardness in this region showed the lowest value.
\end{abstract}

K e y words: aluminum alloys, friction stir welding, heat-affected zone, microstructure

\section{Introduction}

Friction stir welding (FSW) is a novel method of joining materials, patented by the Welding Institute (TWI) in 1991 [1]. This process constitutes a development of the classical friction welding methods. Usually, in the FSW process, no melt of the joining parts occurs, and the weld forms through solid-state plastic flow at elevated temperature [2]. Therefore, FSW can assure the absence of porosity, hot cracking and rather large distortion that are typical defects of the fusion processes [3]. Moreover, it assures the possibility to operate in all positions with no protective gas. At present, several $\mathrm{Al}$ alloys traditionally considered unweldable, such as $2 \times \times \times(\mathrm{Al}-\mathrm{Cu}-\mathrm{Mg}), 6 \times \times \times(\mathrm{Al}-\mathrm{Mg}-$ -Si) and $7 \times \times \times(\mathrm{Al}-\mathrm{Zn})$ aluminum alloys, have been successfully welded by FSW $[4,5]$. However, since the weld nugget zone (WNZ) and thermo-mechanically affected zone (TMAZ) are the obvious transition regions for the friction stir welded aluminum alloys, these regions are still the best important research point [68]. For example, Jones et al. [9] analyzed the correlation between microstructure and microhardness of
FSW joint for AA2024-T351 aluminum alloy by using transmission electron microscopy (TEM). It was found that the very fine $S$ precipitates existed in the thermo-mechanically affected zone (TMAZ). The hardness minimum close to the TMAZ was the result of the coarsening and overaging of the $S$-phase occurring during the thermal cycle. The hardness maximum between these two minima was seen to be due to the presence of very fine $S$-phase. Recent investigations by Genevois and co-workers $[10,11]$ reported precipitation and mechanical behavior of AA2024 aluminum alloys under the T351 and T6 tempers. The initial precipitation is composed entirely of GP zone in TMAZ. That is to say, more researchers considered that the heat-affected zone (HAZ) was not important to analyze and know the relation between the microstructures and properties for the friction stir welded joint. However, in fact, this region has experienced a thermal cycle under the FSW. Thus it should play an assisted role to the mechanical properties of the joint.

In this paper, the microstructure and microhardness distribution of the FSW weld for 2024-T4 aluminum alloys were observed and analyzed by an op- 


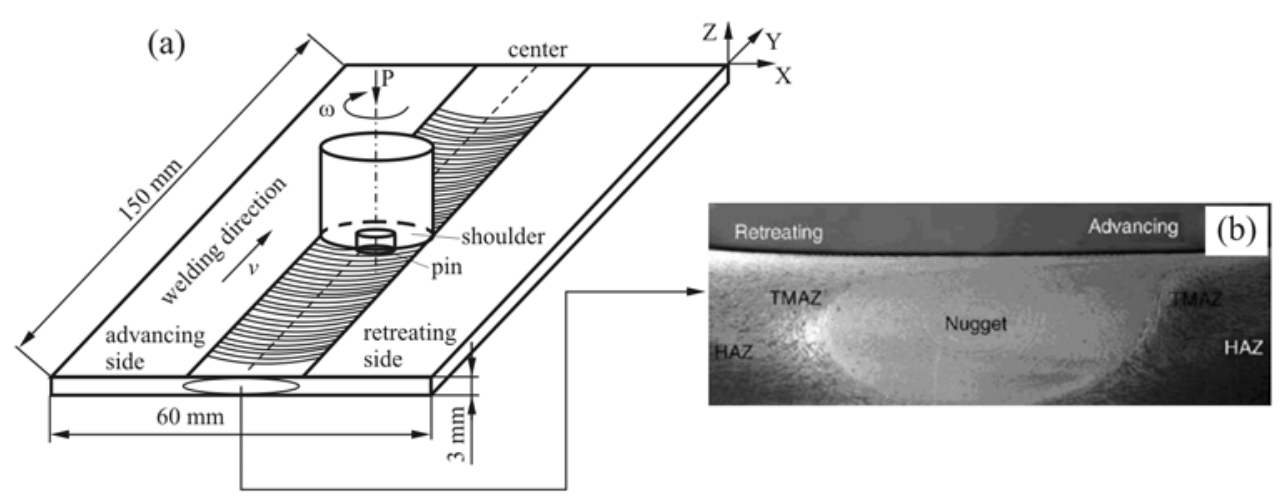

Fig. 1. Friction stir welding process and microstructure: (a) the schematic of the FSW and (b) cross-section image of FS welded joint.

Table 1. Chemical composition of 2024 aluminum alloy (wt.\%)

\begin{tabular}{cccccc}
\hline $\mathrm{Cu}$ & $\mathrm{Mg}$ & $\mathrm{Si}$ & $\mathrm{Fe}$ & $\mathrm{Mn}$ & other \\
\hline $3.8-4.9$ & $1.2-1.8$ & 0.5 & 0.5 & $0.3-0.9$ & $\mathrm{Al}$ \\
\hline
\end{tabular}

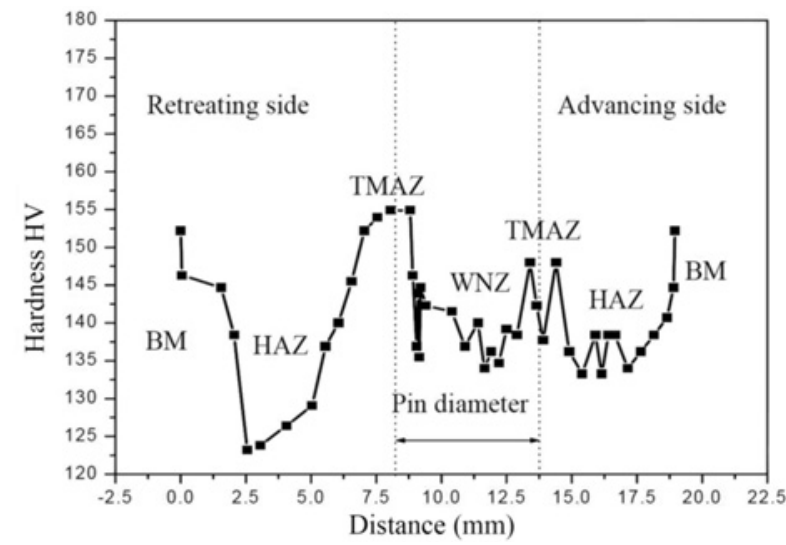

Fig. 2. Microhardness distribution in stir zone of FSW 2024 aluminum alloys.

tical microscopy and microhardness tester. The precipitated phases and dislocations in the HAZ were observed and analyzed using transmission electron microscopy (TEM). This is helpful for further study on the relation between phase constitution and joints performance in friction stir welded aluminum alloys.

\section{Experimental}

The examined joined panels of 2024-T4 aluminum alloys had dimensions of $150 \mathrm{~mm} \times 60 \mathrm{~mm} \times 3 \mathrm{~mm}$. The chemical composition of the test material is shown in Table 1 . The test panels were cleaned with acetone solution. Then, two $3 \mathrm{~mm}$ thick panels were butt welded, using the friction stir welding technique. The
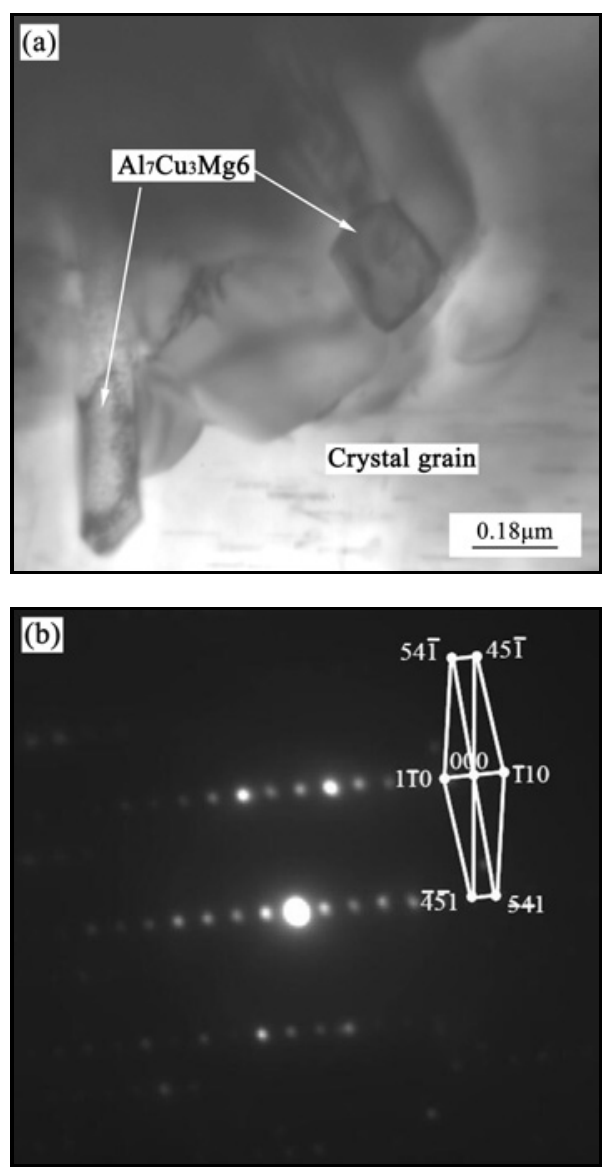

Fig. 3. TEM micrograph and corresponding electron diffraction pattern of the $\mathrm{Al}_{7} \mathrm{Cu}_{3} \mathrm{Mg}_{6}$ [119] precipitated phase in the HAZ close to advancing side of FSW joint: (a) TEM morphology, (b) electron diffraction pattern and schematic index diagram of the panel.

welding direction was parallel to the rolling direction of the sheets. The pin diameter of stir tool was $5 \mathrm{~mm}$. The tool rotational speed and travel speed were $475 \mathrm{rpm}$ and $300 \mathrm{~mm} \mathrm{~min}^{-1}$, respectively. The schematic of the friction stir welding (FSW) and cross section of welded joint are shown in Fig. 1.

A series of specimens was cut from the advanc- 

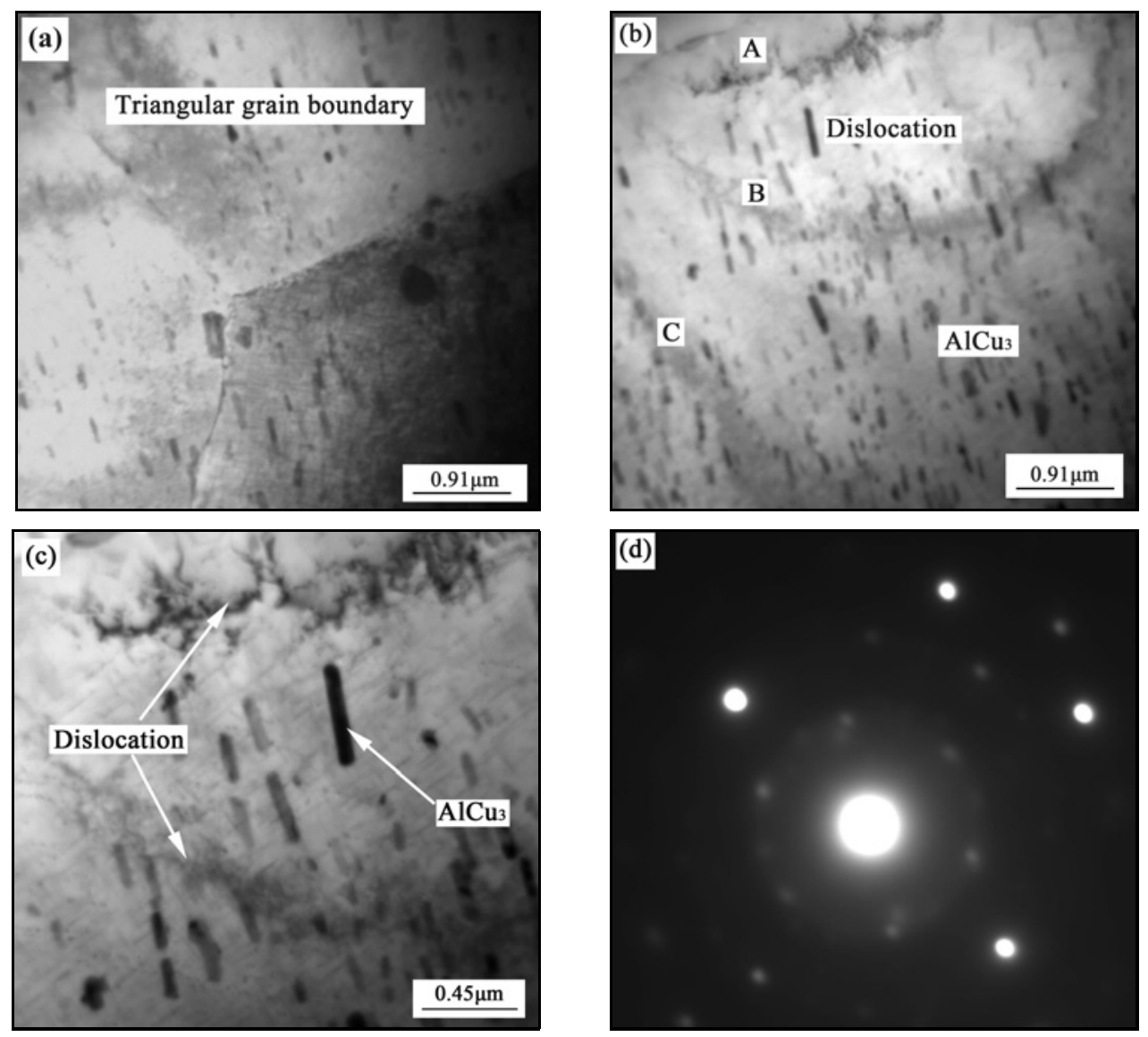

(e)

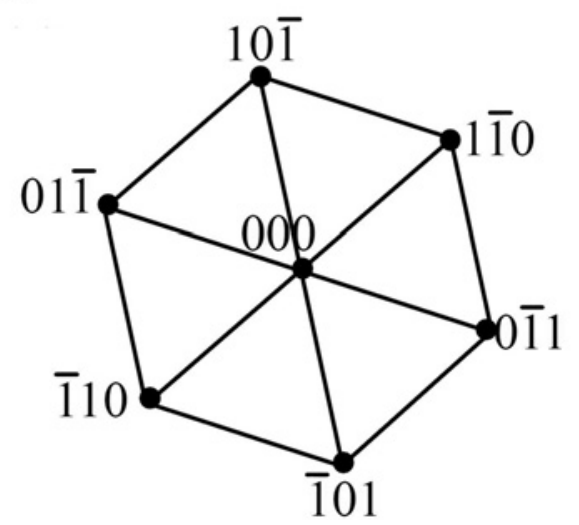

Fig. 4. TEM micrograph and corresponding electron diffraction pattern of the $\mathrm{AlCu}_{3}$ [111] precipitated phase in the $\mathrm{HAZ}$ close to retreating side of FSW joint: (a), (b) TEM morphology, (c) electron diffraction pattern and (d) schematic index diagram of the panel (e).

ing side and retreating side of the heat-affected zone (HAZ) of welded joint, and then these specimens were made into metallographic samples. The samples were cut into foils by linear cutting machine. A double jet electro-polishing technique was used for thin-foil preparation in an electrolyte, containing $\mathrm{HNO}_{3}$ and $\mathrm{CH}_{3} \mathrm{OH}(1: 2)$ at $-20^{\circ} \mathrm{C}$. Microstructural investigation was carried out using transmission electron microscope (TEM) on a JEOL 2011 FX instrument with a W-filament operated at $200 \mathrm{kV}$. The microhardness distribution of the joint was conducted by microhardness experimenter.

\section{Results and analysis}

\subsection{Microhardness distribution}

The microhardness distribution of cross-section for the FSW joint is shown in Fig. 2. The weld of 
FSW joint is composed of three regions, namely HAZ, TMAZ and WNZ.

According to Fig. 2, the hardness distribution is related to the distribution of the cross section structure of FSW joint. The microhardness in the weld decreased from the base metal toward the weld, then began to increase toward the center of the weld (stir zone). This phenomenon was induced under the thermal cycling of FSW. The microhardness of the weld continued to increase to a maximum value (HV 155) across the TMAZ, and then the microhardness shows an abrupt drop of HV20 inside the WNZ region. At last, the lower microhardness, about HV115, is distributed along the $\mathrm{HAZ}$ region at the retreating side. However, in advancing side, the microhardness is close to the WNZ. That is to say, at the retreating side the more obvious microstructure changes may be experienced, such as precipitates and dislocations.

\subsection{Precipitated phase and dislocations in $H A Z$ and base metal}

According to the microhardness analysis, the HAZ close to advancing side shows the lowest hardness distribution. Therefore, the microstructure and precipitated phases in the HAZ of FSW joints for 2024 aluminum alloys and base metal were observed and analyzed by TEM. Figures $3-5$ show the TEM morphology and corresponding electron diffraction pattern of precipitated phase in the HAZ and the typical precipitated phase in the base metal.

According to Fig. 3a, there were some block precipitation particles $\left(\mathrm{Al}_{7} \mathrm{Cu}_{3} \mathrm{Mg}_{6}, Q\right.$-phase $)$ in the $\mathrm{HAZ}$ close to advancing side. The zone axis of $\mathrm{Al}_{7} \mathrm{Cu}_{3} \mathrm{Mg}_{6}$ is $B=[119]$. The ternary phase $\mathrm{Al}_{7} \mathrm{Cu}_{3} \mathrm{Mg}_{6}$ has a body-centered cubic (fcc) structure, and lattice constant is $1.212 \mathrm{~nm}$ (see Figs. 4b,c). The $\mathrm{Al}_{7} \mathrm{Cu}_{3} \mathrm{Mg}_{6}$ was mainly precipitated in the grain boundary of $\alpha$-Al. The $\mathrm{Al}_{7} \mathrm{Cu}_{3} \mathrm{Mg}_{6}$ phase is supposed to increase the hardness of substrate in the HAZ. According to the hardness analysis in Fig. 2, the hardness is close to the WNZ at the advancing side. Therefore, block precipitation particles $\left(\mathrm{Al}_{7} \mathrm{Cu}_{3} \mathrm{Mg}_{6}, Q\right.$-phase) in the HAZ should be the important factor to enhance the hardness at the advancing side of joint.

The TEM morphology and corresponding electron diffraction pattern of precipitated phases in the HAZ close to the retreating side are shown in Fig. 4. The "raindrop" precipitated phases, $\mathrm{AlCu}_{3}$ compounds ( $\beta$-phase), can be observed in the HAZ (see Figs. 4ac). The $\mathrm{AlCu}_{3}$ compounds were mainly distributed in grain crystal. Few precipitates can be observed in the grain boundary. According to Figs. $4 \mathrm{~d}$ and $4 \mathrm{e}$, the zone axis of $\mathrm{AlCu}_{3}$ is $B=$ [111]. The $\mathrm{AlCu}_{3}$ has a body-centered cubic (bcc) structure, and lattice constant is $0.295 \mathrm{~nm}$.

Figure 5 shows the typical $\mathrm{AlCu}_{3}[111]$ precipitated
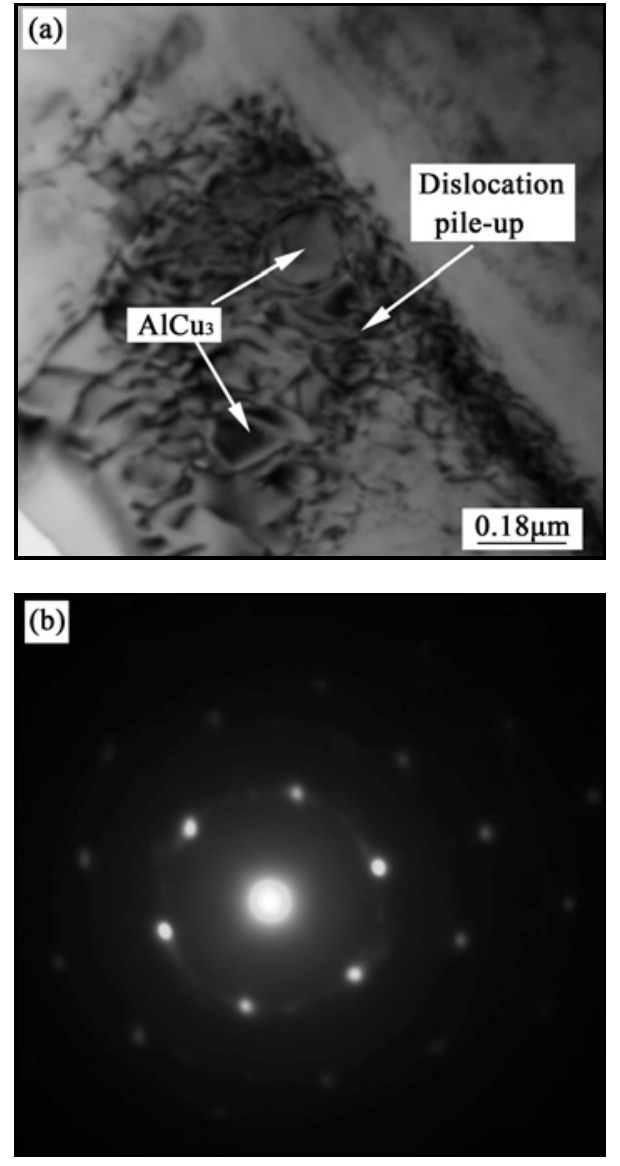

(c)

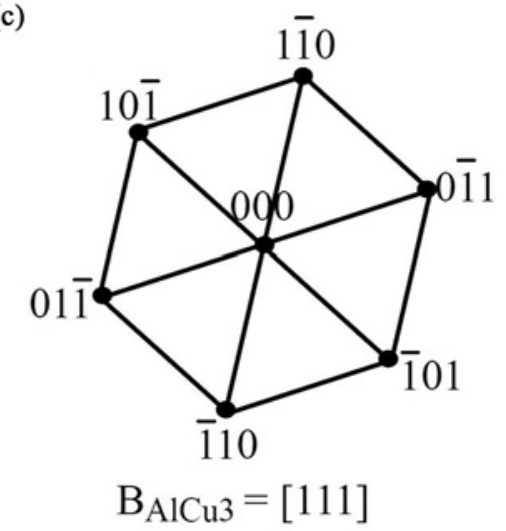

Fig. 5. TEM micrograph and corresponding electron diffraction pattern of the $\mathrm{AlCu}_{3}$ [111] precipitated phase in the base metal: (a) TEM morphology of the $\mathrm{AlCu}_{3}$, (b) electron diffraction pattern and (c) schematic index diagram of the panel (b).

phase in the base metal. These precipitated phases are larger and exist in high-density dislocation pileup compared with the $\mathrm{AlCu}_{3}$ [111] precipitated phase in the HAZ. After the FSW, these dislocations produce the obvious changes. A large number of complex dislocations can be observed in grain crystal (see Figs. 4b,c). The pile-up of dislocations appeared in 
the grain crystal. When these dislocations come into contact with precipitate phases, grain boundary and phase boundary, sometimes the pile-up of dislocations occurs.

The higher deformation and dislocation energy of aluminum alloys may result in the inhomogeneous distribution of dislocations. As a result, multiple dislocations gather in the local region. In other words, these random dislocations in grain crystal can induce the dislocation tangle. Dislocation tangle produces segregation grouping and forms higher dislocation density regions (see Fig. 4b, position A, B and C). Then, these dislocations divide the lower dislocation density regions, resulting in generating cellular subgrain structure formed. The higher dislocation density regions may be as the cell wall. However, the deformation and dislocation energy in the HAZ were lower than in base metal. This typical $\mathrm{AlCu}_{3}[111]$ precipitated phase was also crushed into some fine particles along the dislocations. As a result, the hardness in this region shows the lowest values that stem from the above microhardness test and analysis.

\section{Conclusions}

The microhardness and precipitated phases in the HAZ of FSW joints for 2024 aluminum alloys were observed and analyzed by TEM. The relation among the microhardness, precipitated phases and dislocations is also studied.

The microhardness in the weld decreased from the base metal toward the weld, then began to increase toward the center of the weld. The lower microhardness, about HV115, is distributed along the HAZ region at the retreating side. There were some block precipitation particles $\left(\mathrm{Al}_{7} \mathrm{Cu}_{3} \mathrm{Mg}_{6}\right)$ in the $\mathrm{HAZ}$ close to the advancing side. The precipitated phases, $\mathrm{AlCu}_{3}$ compounds ( $\beta$-phase), can be observed in the HAZ close to retreating side. With the precipitation of $\mathrm{AlCu}_{3}$ phase, a large number of complex dislocations can be observed in the grain crystal. The pile-up of dislocations appeared in the grain crystal. Compared with the base metal and hardness distribution, some block precipitation particles $\left(\mathrm{Al}_{7} \mathrm{Cu}_{3} \mathrm{Mg}_{6}\right.$ phase $)$ in the $\mathrm{HAZ}$ could enhance the hardness in the advancing side of joint. The typical $\mathrm{AlCu}_{3}$ [111] precipitated phases in base metal are larger and exist in high-density dislocation pile-up compared with the HAZ. These dislocations were divided into the lower dislocation density regions and precipitated phase was also crushed into some fine particles along the dislocations. As a result, the hardness in this region shows the lowest values.

\section{Acknowledgements}

This work was financially supported by the Shandong Provincial Natural Science Foundation, China (Grant No. ZR2016JL017 and No. ZR2016EEB31) and National Natural Science Foundation of China (Grant No. 51305240).

\section{References}

[1] Thomas, W. M., Nicholas, E. D., Needham, J. C., Murch, M. G., Temple-Smith, P., Dawes, C. J.: International Patent Application No. PCT/GB92/02203 and GB Patent Application No. 9125978.8. London, UK Patent Office 1991.

[2] Jeff, D.: Weld. J., 85, 2006, p. 42.

[3] Mahoney, M. W., Rhodes, C. G.: Metall. Mater. Trans. A, 28, 1998, p. 1955. doi:10.1007/s11661-998-0021-5

[4] Sato, Y. S., Kokawa, H., Enomoto, M.: Metall. Mater. Trans. A, 30, 1999, p. 2429. doi:10.1007/s11661-999-0251-1

[5] Sutton, M. A., Yang, B., Reynolds, A. P., Taylor, R.: Mater. Sci. Eng. A, 323, 2002, p. 160. doi:10.1016/S0921-5093(01)01358-2

[6] Cabibbo, M., Meccia, E., Evangelista, E.: Mater. Chem. Phys., 81, 2003, p. 289. doi:10.1016/S0254-0584(02)00604-1

[7] Sato, Y. S., Park, S. H. C., Kokawa, H.: Metall. Mater. Trans. A, 32, 2001, p. 3033. doi:10.1007/s11661-001-0178-7

[8] Liu, P., Liu, G. L., Deng, Y., Li, J. N., Jing, C. N., Feng, K.Y.: Kovove Mater., 54, 2016, p. 363. doi: 10.4149/km_2016_5_363

[9] Jones, M. J., Heurtier, P., Desrayaud, C., Montheilet, F., Allehaux, D., Driver, J. H.: Scripta Mater., 52, 2005, p. 693. doi:10.1016/i.scriptamat.2004.12.027

[10] Genevois, C., Deschamps, A., Denquin, A., DoisneauCottignies, B.: Acta Mater., 53, 2005, p. 2447. doi:10.1016/j.actamat.2005.02.007

[11] Genevois, C., Deschamps, A., Vacher, P.: Mater. Sci. Eng. A, 415, 2006, p. 162. doi:10.1016/j.msea.2005.09.032 